\title{
Digital Pathology and ICT in Medical Education in the Pre-COVID Era: Measuring the State of Readiness of Medical Students in a Nigerian Medical School for the Changing Technological Landscape
}

\author{
Ima-Abasi E. Bassey, Edoise M. Isiwele, Cornelius C. Chukwuegbo, Ima-Obong A. Ekanem
}

\section{ABSTRACT}

Background: Information Communication Technologies (ICTs) have caused significant improvement in the practice and teaching of medicine worldwide. The novel coronavirus disease (COVID 19) pandemic has heightened the need for increased development and improvement in ICT skills and infrastructure. ICTs are causing a revolution in the way Pathology is practiced and taught worldwide. This study was carried out to evaluate the utility of ICTs in undergraduate pathology education in a tertiary institution in Nigeria.

\begin{abstract}
Materials and Methods: This was a cross sectional study in which a structured questionnaire was used to assess students' access to ICT, ICT skills and perceptions regarding ICT in pathology education. Questions regarding learning challenges and knowledge of pathology related resources and the current state of utilization of computer based/digital tools in pathology education in the institution were also examined. Data was analysed using SPSS version 20 and reported in charts.
\end{abstract}

Results: Questionnaires were administered to 146 students out of which 97 responded. Only $44 \%$ of the students had personal computers with $24 \%$ using their computers daily and $69 \%$ having internet connectivity. Most were proficient in Word processing $(84 \%)$ and Email $(80 \%)$, while very few had programming or database skills. Eighty-nine percent $(\mathbf{8 9 \%})$ considered ICT as being useful in pathology learning, while $65 \%$ considered ICT as being more effective than traditional learning methods. Gross demonstrations were rated as being superior to digital images in gross pathology by $55 \%$. The most commonly used ICT tools by the students were photomicrographs, online lecture notes, images and tutorials with interactive ICT tools (webinars, teleconferencing and simulations) hardly being used.

Conclusion: The need for formal training in relevant ICT skills in specific content areas is very necessary in our environment, more so now with the appearance of the COVID - 19 pandemic on the scene.

Keywords: COVID 19, Digital Pathology, Information Communication Technologies, Medical education.

\section{INTRODUCTION}

Information Communication Technologies (ICTs) have changed the ways in which medicine is practiced and taught. In the past, ICT was centered on word processing, but this has rapidly changed with improving technology. The increasing availability and relative affordability of computers as well as the advent of the worldwide web have greatly facilitated this
Published Online: October 30, 2020

ISSN: $2593-8339$

DOI: $10.24018 /$ ejmed.2020.2.5.500

Ima-Abasi E. Bassey

Department of Pathology, College of Medical Sciences, University of Calabar, Nigeria.

Edoise M. Isiwele*

Department of Urology, University of Calabar Teaching Hospital, Calabar, Nigeria.

(e-mail: eddieisiwele@yahoo.com)

Cornelius C. Chukwuegbo

Department of Pathology, Federal Medical Centre, Umuahia, Nigeria. Ima-Obong A. Ekanem

Department of Pathology, College of Medical Sciences, University of Calabar, Nigeria.

*Corresponding Author development [1]-[3]. The world of the 21 st century doctor is more multilayered with more online existences and real world life connections for everyday professional tasks. Several studies by Nigerian authors have highlighted the need for an upgrade in ICT knowledge, skills and infrastructure as well as development of robust policies on digitalization of data in order to improve service delivery in healthcare in the country [4]-[6]. The novel coronavirus disease (COVID 19) pandemic has further brought to the fore the need for 
increased development and improvement in ICT skills and infrastructure. There has been an upsurge in the use of ICT in routine daily life as well as in medicine and medical education in an effort to continue communication while maintaining social distancing. The landscape in medical education is thus changing rapidly. The evolution of ICTs has greatly changed the practice of pathology. Digital pathology has been defined as the electronic capture, management, analysis and distribution of gross or microscopic specimens, encompassing the use of digital images as well as telepathology [7]. It has come to revolutionize the way Pathology is practiced and taught worldwide. It also follows therefore, that there would be a dramatic shift in the skill-sets required for the workplace. It has been agreed that undergraduate education as far as possible should be designed on the basis of challenges the students are expected to encounter throughout their career and the expectations of the society at large [8]. The undergraduate medical curriculum is not exempt. Pathology education stands to benefit greatly from computer technology because it is a visually intensive and detail oriented discipline where diagnostic competence is based upon repeated visual experience. Useful ICT learning resources include photomicrographs, gross images, multimedia (simulations, animations), internet, CD ROMs and virtual microscopy. The aim of this paper was to evaluate the utility of ICT in undergraduate pathology education in the University of Calabar, Nigeria.

\section{METHODOLOGY}

This was a cross sectional, questionnaire-based study conducted at the University of Calabar, Nigeria. The study participants were fifth year medical students of the University. A structured, anonymous questionnaire to assess students' access to ICT, ICT skills and perceptions regarding ICT in pathology education was administered to participants in a classroom setting. Free text questions regarding learning challenges and knowledge of pathology related resources were included. The current state of utilization of computer based/ digital tools in pathology education in the institution was also examined. Informed consent was obtained from all participants. Data was analyzed using SPSS version 20 and reported in charts.

\section{RESULTS}

Questionnaires were administered to 146 students out of which 97 responded, giving a response rate of $66.4 \%$.

\section{A. Access to ICT}

Forty-four percent (44\%) of the students were found to have personal computers/ laptops with only $24 \%$ using their computers daily and $69 \%$ having internet connectivity (personal or public access). Up to $64 \%$ of the students used the internet two or more times weekly. Majority of the students $(75 \%)$ used internet more for educational than recreational purposes

\section{B. ICT skills}

Majority rated themselves as being most proficient in Word processing (84\%) and Email (80\%), while very few had programming and/ or database skills

\section{Perceptions regarding ICT in pathology education}

Eighty-nine percent (89\%) agreed that ICT has been useful in learning pathology generally while $65 \%$ agreed that ICT was more effective than traditional learning methods in the overall learning of pathology. While $73 \%$ preferred the use of photomicrographs to traditional glass slides in microscopy, $55 \%$ rated gross demonstrations as being superior to digital images in gross pathology

\section{Current state of utilization of computer based digital tools}

The most commonly used ICT tools by the students for self-learning in pathology were photomicrographs, online lecture notes, images and tutorials $(71 \%)$. Interactive ICT tools (webinars, teleconferencing, simulations) were hardly ever used. Most online learning activities were not a part of the course curriculum. Lectures were often given using PowerPoint presentations and practical classes involved the use of glass slides, photomicrographs, gross pots as well as gross images.

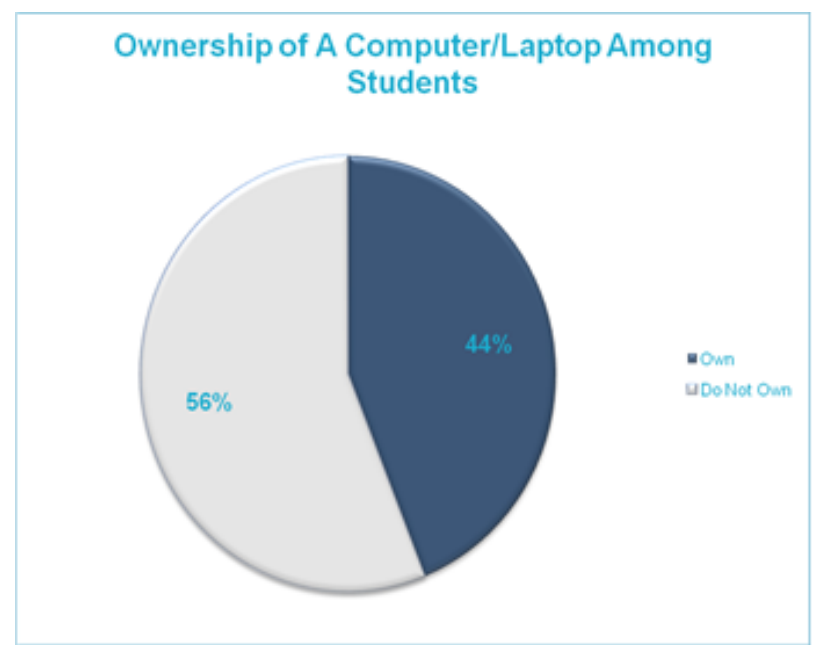

Fig. 1. Ownership of computer/ laptops among students.

\section{Internet Connectivity Among Students}
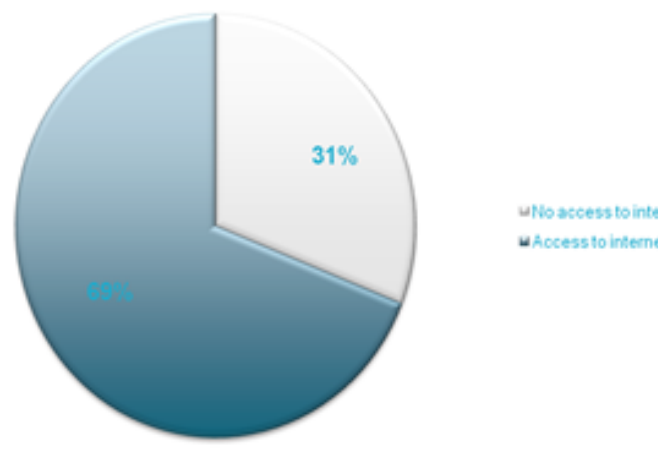

Fig. 2. Internet connectivity among students. 


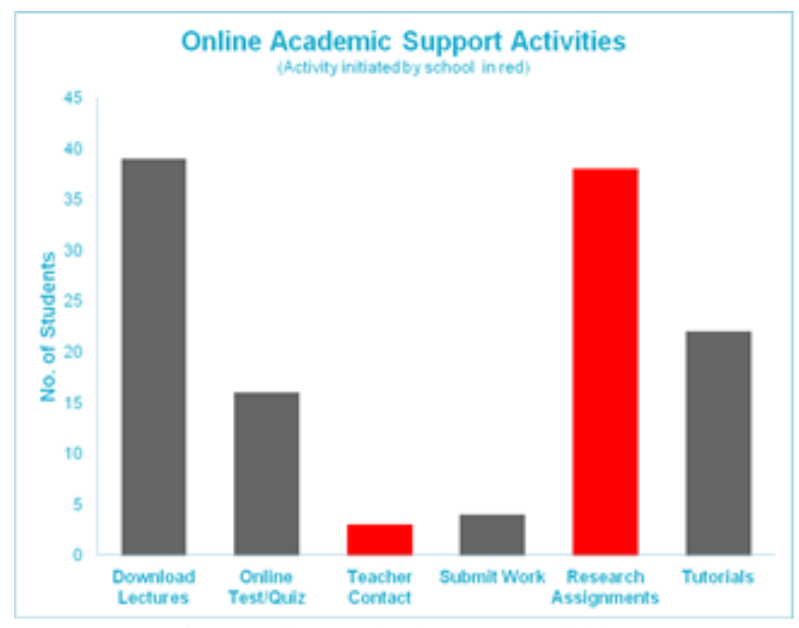

Fig. 3. Online academic support activities.

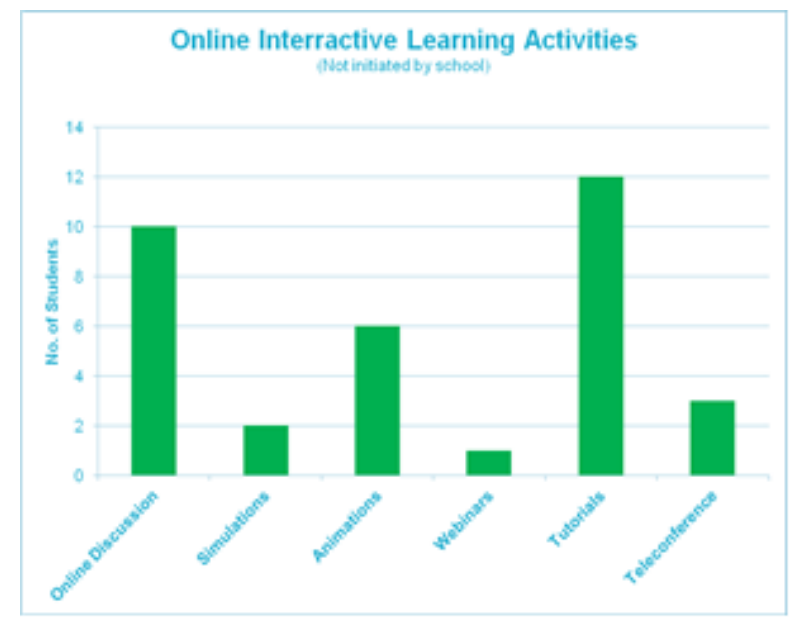

Fig. 4. Online interactive learning activities.

\section{DISCUSSION}

Digital pathology is said to be the next frontier in the learning and practice of pathology $[9,10]$. Its applications in education include medical school teaching, slide seminars/ conferences and pathology workshops. Its applications in Pathology practice include image analyses, proficiency testing, intra-operative evaluation, conferences, consultations, and primary histologic diagnoses. All these call for a reasonable degree of digital literacy. Judging from the number of students who have laptops/ PCs (44\%) as well as internet connectivity (69\%), ICT infrastructural issues have to be addressed so as to ensure that all students have access to internet at the institutional level. A similar study carried out in a medical school in South India showed that $95.6 \%$ of the medical graduates studied had access to and use computers fairly regularly, while $46.2 \%$ actually used them every day [11]. Following the negative effect of COVID 19 on academic activities, there has been a shift to mostly online academic activities in the developed world. Conversely, in most developing countries where access to ICT infrastructure is low, academic activities have virtually ground to a halt with only few being able to meet up with the demands of online educational activities. There must be a more decisive move by government and private bodies to improve access to these facilities as the world has become transformed following the COVID 19 experience. More of virtual than face-to-face interaction will be the way to go in the post COVD era and efforts must be made to meet this current challenge.

Our results also revealed that most online academic support and learning activities carried out by the students were self-directed learning and not as a result of routine demands of the pathology course. As the landscape is changing, this trend has to change also. Digital pathology is very dynamic with the next decade expected to bring several developments [12] into which we must key. Curriculum modification is necessary at this point to ensure that school faculties incorporate online/ virtual academic activities albeit, gradually but steadily. Obviously sheer existence of the technology alone is not enough as all pathology course lecturers have laptops and broadband internet access. Personal development is very key in this regard to ensuring that necessary technological skills are developed. Other important determinants of successful ICT integration into teaching include teachers' preparedness which goes beyond how to use ICT instructional materials to include ability to prepare, use and appropriately select teaching materials that would better build knowledge and develop critical and creative thinking. The build up towards incorporating digital pathology fully into our curriculum must be a determined and deliberate one.

\section{CONCLUSION}

There is still quite a gap between the possibilities that exist for a reasonable integration of ICT in the teaching process and the present utilization of these technologies. There is need for formal training in relevant ICT skills in specific content areas as 'appropriateness' of technology varies from subject to subject. A digitally aware and enabling leadership is required to drive a digitally empowering agenda. This has become glaringly necessary with the appearance of the COVID 19 pandemic on the scene with the challenges that have come with it. The need for Effective Change Leadership in medical institutions with regards to ICT has become paramount in order to provide medical education that measures to the requirements of the $21^{\text {st }}$ century.

\section{ACKNOWLEDGMENT}

We wish to thank the fifth year medical students and pathology course lecturers that participated in this study. Our gratitude goes to Dr. Joseph Ogbeche for assisting with administration of the questionnaires

\section{REFERENCES}

[1] Houshyari AB, Bahadorani M, Tootoonchi M, Jacob J, Gardiner Z. Medical Education and Information and Communication Technology. J Educ Heal Promot. 2020;1(3):1-13.

[2] Ward JPT, Gordon J, Field MJ, Lehmann HP. Communication and information technology in medical education. Lancet. 2001;357:7926.

[3] Karsenti T, Charlin B. Information and Communication Technologies (ICT) in Medical Education and Practice : The Major Challenges. Int J Technol High Educ. 2008;5(2):68-81.

[4] Idowu B, Ogunbodede E, Idowu B. Information Communication \& Technology In Nigeria: The Health Sector Experience. J Inf Technol Impact. 2003;3(2):69-76.

[5] Gambo IP, Soriyan AH. ICT Implementation in the Nigerian Healthcare System. IT Pro. 2020;19:12-5.

[6] Bassey I-A, Isiwele EM, Ayi D. Prognostication studies of prostate cancer in Black Africa: Findings from Calabar, South-South, Nigeria. 
Int J Cont Med Res. 2018;5(5):E1-5.

[7] Bellis M, Metias S, Naugler C, Pollett A, Jothy S, Yousef GM. Digital pathology: Attitudes and practices in the Canadian pathology community. J Pathol Infom. 2013;4(3).

[8] Darling-hammond L, Flook L, Cook-harvey C, Barron B, Flook L, Cook-harvey $\mathrm{C}$, et al. Implications for educational practice of the science of learning and development. Appl Dev Sci [Internet]. 2020;24(2):97-140. Available from: https://doi.org/10.1080/10888691.2018.1537791

[9] Cooper LA, Carter AB, Farris AB, Wang F, Kong J, Gutman DA, et al. Digital Pathology: Data-Intensive Frontier in Medical Imaging. Proc Inst Electr Electron Eng. 2014;100(4):991-1003.

[10] Soenksen D. Digital Pathology: A New Frontier in Education. Lab Med. 2008;39(2):73-7.

[11] Seetharaman N. Assessing Computer Skills among Graduate Medical Students in South India Assessing Computer Skills among Graduate Medical Students in South India. Nat J Res Com Med. 2012;1(1):1-60.

[12] Diest PJ Van, Al-janabi S. Digital pathology: current status and future perspectives. Histopathology. 2012;61(1):1-9. 